\title{
Poisoned Grapes, Mad Cows and Protectionism
}

\author{
EduARdo M.R.A. ENGEL*
}

\begin{abstract}
This paper studies two episodes where a ban on imports was imposed to safeguard people's health. The first case is the poisoned grapes crisis involving Chile and the United States in 1989. The second is the "mad cows" dispute, which broke out in 1996, between the United Kingdom and the European Union. These case studies motivate a new definition of "protectionist measure" which is applied to argue that the European Union's ban on British beef exports was not protectionist, while the US ban on Chilean fruit possibly classifies as such a measure.
\end{abstract}

Keywords: Ban on exports; non-tariff trade barrier; protectionism; protectionist measure.

JEL classification: F13, F14, F15, Q17. 


\section{INTRODUCTION}

A good definition of "protectionist measure" would be useful from both a conceptual and a practical point of view. In fact, in order to better define the elements of the new faces of protectionism we need a clear sense of what constitutes a protectionist measure. From a practical point of view, the effective resolution of disputes, whether these occur within multilateral organizations like the World Trade Organization or stem from free trade agreements such as NAFTA, depends heavily on being able to decide when a measure is protectionist.

This paper proposes a new definition, in which a measure becomes "protectionist" when it differs from the measures that would otherwise have been taken, if the welfare of all countries affected by the measure had been considered. I discuss the implications of this new definition in the context of two case studies. The first deals with the poisoned grapes crisis between Chile and the US in 1989. The second is the "mad cows" dispute, which broke out in 1996, between the UK and the European Union.

On March 13th 1989, the US Food and Drug Administration (FDA) announced it had found two grapes from Chile contaminated with cyanide. Without consulting the Chilean Government, the FDA promptly banned Chilean fruit, triggering the "poisoned grapes crisis" as it became known, which hit one of Chile's main exports hard. Four days later, following tough bargaining between government representatives from Chile and the US, and the signing of agreements on strict sanitary controls, the US formally ended the embargo. In the meantime, Chile had lost over US\$400 million. Section 2 describes this case in detail.

In the second case, on March 27th 1996 the European Union imposed a worldwide ban on beef exports from the United Kingdom, thereby setting off the "mad cow crisis." Scientific evidence published at the time suggested that there was a real possibility that mad cow disease, which causes fatal encephalopathy, could affect people. Section 3 describes the "mad cows" case. 
In both cases, the main purpose of the resulting embargo was to safeguard people's health, so one could reasonably argue that these measures were not protectionist. However, Section 4 argues that using the new definition of "protectionist measure" proposed in this paper, one of the bans would not qualify as protectionist, whereas the other would. Finally, Section 5 presents the paper's main conclusions. Any reader who recalls the main events associated with both cases is welcome to skip directly to Section 4 for the main thesis of this paper.

\section{THE POISONED GRAPES CRISIS ${ }^{1}$}

\subsection{The March Crisis}

\subsubsection{The Embargo}

On Monday March 13th 1989, the FDA announced it had detected in the port of Philadelphia two Chilean grapes containing cyanide. Although the dose was not lethal, the FDA issued a national news release announcing its decision to quarantine all fruit from Chile headed for the US market, calling on stores to take it off their shelves and consumers to avoid consuming the fruit. This measure affected half of Chile's production for the season, already being loaded for shipment or on its way to the US. It also affected Chilean fruit that had already entered the country and was then being stored in commercial distributors' refrigerators or warehouses, and whose destruction was now recommended. The FDA decision to ban the fruit and to publicize this throughout the country created real panic. Just hours after Dr. Frank Young, FDA Commissioner, made the announcement, the main supermarket chains had removed the fruit from their shelves. The ban on Chilean fruit due to cyanide-contaminated grapes became the lead story on national television news and in newspapers throughout the country.

Media accounts after the event revealed that, during the week leading up to the announcement, the US embassy in Santiago had received several telephone calls threatening 
to poison fruit destined for the North American and Japanese markets. This initially led to some restrictions on Chilean fruit entering the US, but these were lifted a few days later when exhaustive checks found nothing, and in light of what the US Government called "notable safety measures adopted in Chile." Knowledge of these precautionary measures was restricted to the authorities of each country and exporters, with no information provided to the public at large.

FDA checks were stepped up, however, after a second threatening call, with more than 100 officials being deployed at exporters' expense to inspect and check approximately $10 \%$ of the 600,000 boxes of Chilean fruit arriving daily at US ports. On the morning of March 12th, FDA inspectors going through cargo from the "Almería Star," containing produce exported by Julia Saavedra of Curacaví, Chile, found two grapes showing signs of tampering in a box of Flame Seedless "Crispy." Specifically, the grapes were discolored, with a ring of crystalline material surrounding an apparent pinprick. Laboratory analysis confirmed the presence of cyanide, although the dose would not have been lethal to human beings. Due to cyanide's high volatility in an acid medium such as a grape, technicians could not determine the original dose injected.

In Chile, the measure caused huge public outcry, because of the enormous losses it would cause. Share prices fell immediately, with shipping company stocks, whose prices dropped $10.7 \%$, the most affected. The US ban on Chilean fruit was felt immediately not only by producers, but all the way along the production chain of what had become a flourishing fruit export industry. More serious still was the damage to foreign consumers' confidence in Chilean fruit. Such a public measure threatened to produce not only major financial losses but also the loss of entire markets, as consumers were becoming particularly sensitive to food additives generally.

That same Monday 13th, in a nationally broadcast address, Carlos Cáceres, Chile's Minister of the Interior, told the people of Chile that while he did not support the decision by US authorities, he did understand their concern for consumers' health. He called the incident a terrorist attack supported by the Communist Party and announced an 
investigation to identify those responsible. Similarly, he announced that security measures would be strengthened throughout the fruit processing chain, from the moment of harvest until its arrival at the port of destination.

The military government moved rapidly to set up negotiations at the highest level in the US, aimed at obtaining a speedy reversal of the ban. With this in mind, by the next day, an official delegation, headed by Foreign Minister Errázuriz, was on its way to Washington, where it began an intensive lobbying effort directed at members of congress, business leaders and US Government officials, who were informed of the measures' impacts, as well as safeguards adopted by Chile to protect its exports. In a news conference, Senator Heinz $^{2}$ underlined the urgent need for a rapid solution, in view of the damage to both US and Chilean interests. Before the FDA, he argued in favor of a plan to restore confidence in Chilean produce.

Three days after the ban, James Baker, the US Secretary of State, met with Chile's Ministers of Foreign Affairs and Agriculture and they agreed to work together to find solutions to the critical situation affecting Chilean fruit exports. They announced that a team of FDA experts would travel to Santiago to confirm security controls on shipments. In response to stories in the Chilean media suggesting political motives behind the FDA's measure, Baker said that the decision was made "strictly on the grounds of health and safety and not, in any way, for political motives," adding that both Chilean producers and US citizens' and interests were being hurt.

The Chilean Agriculture Minister and the FDA Commissioner agreed in principle on a solution to the crisis, and technical experts from both countries began to draw up the details. On Friday March 17th, four days after the embargo was imposed, and following tough negotiations and agreements on strict sanitary controls, authorities announced that Chilean fruit exports to the US market would resume, as of March 21st. 


\subsubsection{The Embargo's Economic Impact}

The FDA embargo hit as the export season peaked, when $45 \%$ of the fruit had already left the country. This was also the moment when agricultural sector debts were at their highest. The Superintendency of Banks reported that when the ban was announced export sector debts with private local banks amounted to almost US $\$ 400$ million.

Although it was short (just four days), the ban's impact on the economy was widespread. An Official Report on the Grapes Case, prepared by the Chilean Congress, confirmed exporters' estimates that private-sector losses reached some US $\$ 330$ million.

The sheer magnitude of losses forced the military government to support producers and exporters. To provide some relief, and prevent the fruit export sector's collapse, on March 19th General Pinochet announced measures to bail out the export sector, including compensation and special lines of credit to producers and exporters. Measures also included a debt swap mechanism, which allowed exporters to buy Chilean foreign debt papers abroad, then trading at $60 \%$ of face value, with the Central Bank of Chile buying them back at par. At the same time, the Association of Banks agreed to let exporters roll over financial liabilities falling due between March 13th and June 30th.

These measures, according to a report by the Chilean Chamber of Deputies, cost the Treasury some US $\$ 198.2$ million, ${ }^{3}$ while a Central Bank report stated that US $\$ 263$ million from the Copper Stabilization Fund were used to alleviate the crisis. ${ }^{4}$

One can argue that just announcing problems with Chilean grapes would have large costs for Chilean exporters, even in the absence of an embargo. ${ }^{5} \mathrm{~A}$ long run reduction in the demand for Chilean fruit in the US would indicate that the FDA measure had a long run cost for Chilean exporters, beyond the costs associated with announcing the finding of contaminated grapes.

Table 1 provides some interesting information in this respect. It shows yearly growth rates of the volume of Chilean grape exports, both to the US and to the rest of the world. ${ }^{6}$ Both in the years before and after the embargo, Chilean grape exports to the US generally grew slower than exports to other countries. Since the poisoned grapes episode 
took place in the US, it is reasonable to conjecture that any lasting effect would reflect itself in a significant increase of the difference in growth rates. Table 1 shows that this is not the case: the average difference in growth rates increased only slightly between 1986-8 and 1990-2, from 7.7 to $10.6 \%$. This suggests that a significant fraction of the costs born by Chile were losses during the year of the embargo. ${ }^{7}$

\subsection{New Investigations and Revelations}

\subsubsection{Accusations and New Information}

Once the US Government lifted the embargo, the media in both countries revealed new information, publishing allegations and raising suspicions about the motives of those taking the measures in the US.

Some US newspapers suggested that one possible explanation for the excessive zeal of the FDA (supported by the White House) was the bitter experience of the Bush administration in December 1988, when it took no measures in response to a bomb threat affecting a PanAm flight over Scotland and the plane blew up, killing 207 people. Dr. Young acknowledged that this event had influenced his decision. ${ }^{8}$

In July 1989, four months after the embargo, Herb Denenberg, a journalist with CBS, did a three-part series for Philadelphia's Channel 10 news network on the poisoned grapes case. After two months' research with a team of experts, he questioned the alleged poisoning of the grapes, arguing that FDA analyses had been inconclusive and suffered from numerous defects which violated their own procedural rules.

On November 16th 1989, the Wall Street Journal published an extensive report by journalist Bruce Ingersoll, presenting evidence that strongly suggested the fruit had been poisoned in the US and not in Chile.

Chilean and US experts argued that the grapes couldn't have been poisoned in Chile, nor could cyanide have been injected. Some specialists cast doubt on the "miraculous" way in which the two contaminated grapes were found amidst a shipment of millions of bunches 
of grapes. Among them, Herman Chernoff, professor of statistics at Harvard University, noted that just 26 of the 4045 pallets in the "Almería Star" came from Julia Saavedra's vineyard and yet a large number of boxes from her vineyards were among those inspected. He went on to suggest that this indicated that the FDA had prior information on where to look for the poisoned grapes, adding that the probability of Mrs. Saavedra's vineyards being so over-represented in a random sample was less than one in ten thousand. ${ }^{9}$

Finally, critics also attacked the unusually harsh measure taken by US authorities in banning all exports, compared with the insignificant quantity of poison actually discovered. Measures were taken without considering the disastrous impact they would have on the Chilean economy. They also pointed out that the FDA had never taken such a drastic step before, even faced with more serious cases.

\subsubsection{The Quest for Compensation}

¿From 1990 on, the newly-elected coalition government of the Concertación, together with fruit exporters and producers, focused their energies on obtaining compensation from the US Government for Chile's economic losses. Legal action was backed up by numerous examples of irregularities and negligence committed by FDA officials when making their decision, in the eyes of the Chilean Government and exporters, as well as arguments supporting their belief that the fruit had been contaminated outside Chile.

After studying several courses of action, on February 28th 1991, President Aylwin's government together with exporters launched separate administrative and legal actions (for US $\$ 246$ and US $\$ 212$ million respectively) against the FDA for material damages resulting from the US' measure.

In August, the FDA rejected the Chilean claims. In February 1992, the Chilean private sector filed a lawsuit in the Federal Court of the District of Philadelphia. However, the US Government invoked "jurisdictional immunity" to reject legal proceedings against it, and on December 30th 1992 the court's preliminary ruling came down against the Chilean claim. In view of this, and after studying other alternatives, on March 30th 1993 
the Aylwin Government invited its US counterpart to use the 1914 Bryan-Suárez Mujica Treaty, to resolve their differences. ${ }^{10}$ Three months later the US Government rejected the Chilean request, suggesting the alternative of using diplomatic channels, specifically the creation of a binational working group. The Chilean Government accepted this proposal, with negotiations culminating, in February 1994, in the proposal of a series of tariff compensations to favor Chilean exports. These measures were rejected outright by producers and exporters, while President Frei's government described them as insufficient. Thus, the work of the binational commission ground to a halt.

At the same time, lawyers representing Chilean producers appealed the initial ruling in Philadelphia's Appeals Court, achieving their first (and so far only) judicial victory (February 25th, 1994). The US government in turn appealed and, in late 1995, the US Supreme Court issued a final ruling on the case, rejecting Chile's petition to have the US administration brought to trial for the ban. In response, Chile's Foreign Minister appointed Ambassador Fabio Vio to coordinate an ad hoc commission to report on possible courses of action open to Chile. This commission also recommended using the diplomatic route. To this day, the case remains unresolved, and continues to be a major problem in Chile/US relations.

\subsection{What Caused the Embargo?}

To understand the origin of this crisis, we need to answer two questions. Firstly, who contaminated the two grapes found by the FDA, on Monday March the 13th? Secondly, assuming that the FDA acted in good faith, why, once the grapes had been found, did the

Bush administration apply so drastic a measure with such grave economic consequences for Chile?

In terms of who contaminated the grapes and why, there are three main hypotheses. First, there is the conspiracy and sabotage theory that several public figures and organizations have insisted upon. The facts that have come to light suggest that there could have been a political motivation behind the FDA decision. What might this have been? Some 
people suggest a strategy to intimidate General Pinochet, to prevent him from making any changes to plans for a return to democracy, following his defeat at the polls in the 1988 plebiscite. This theory suggests that the US Government, concerned that Pinochet might try to stay in power beyond the deadline set out in the 1980 constitution, put together a plan to apply pressure to a highly sensitive area of the economy.

Secondly, there is the protectionist hypothesis, according to which the embargo responded to strong pressures being exerted on the US Congress by Californian fruit growers, anxious to protect themselves from growing competition from Chilean fruit. This hypothesis has been rejected by official circles in Chile. However, some elements suggest a degree of collusion between the State Department, US health agencies and the US Congress to restrict the entry of Chilean fruit. A controversial telex sent by the Secretary of State to countries importing Chilean fruit shortly after the crisis erupted, as well as the curious behavior of the US agricultural attaché in Saudi Arabia, who contacted importers in that country to persuade them to cancel contracts with Chilean exporters, ${ }^{11}$ lends some support to this hypothesis. However, the protectionist hypothesis is ultimately unconvincing, because Chile's grape export season does not overlap with grape production in California. Furthermore, neither Chilean nor North American producers can significantly lengthen their export seasons, making potential competition between producers in the two countries unlikely. To sustain this hypothesis, therefore, requires demonstrating irrational behavior on the part of agricultural producers in California.

A third hypothesis suggests negligence by the FDA. Numerous anomalies and unanswered questions point to the possibility that FDA researchers, concerned about telephone threats in Santiago, may have been testing the effects of cyanide in fruit. According to this hypothesis, one cannot rule out the possibility that the tainted grapes formed part of experiments being carried out by the FDA, and that they got mixed up with other grapes that were being examined for preventive reasons.

This leads us to ask whether the FDA, while not involved in the actual tampering, can be blamed for applying a disproportionate measure that caused significant damage to the 
Chilean economy. What could explain an attitude of this nature? Elements singled out by the media at the time include the weakness of Commissioner Young's position, the lesson of the attack on the PanAm aircraft, and pressure from consumer organizations alarmed at the FDA's failure to ban apples with "Alar." 12 Nor can we discard the possibility that the FDA may have agreed to take part in a political operation mounted inside the federal government.

Finally, it is worth questioning whether Commissioner Young's decision to apply an embargo was a rational response. To do this, we must examine the facts he had at his command at the time, rather than information that became available months, days or even hours later. This analysis clearly assumes that Young did not participate in any plot. When news of the discovery of two poisoned grapes reached him on Monday March 13th, how would Commissioner Young have reasoned? Section 4 argues that this last explanation is the most convincing, and that any official in the position of FDA Commissioner would have acted the same way. However, this does not change the fact, as also argued in that section, that Commissioner's Young measure can be classified as protectionist.

\section{THE MAD COWS CASE ${ }^{13}$}

\subsection{The Embargo}

On March 27th 1996 the European Union (EU) imposed a worldwide ban on beef exports from the UK, thereby giving rise to the so-called "mad cow crisis." In 1995, exports of British beef and related products had reached US\$1 billion.

Just one week earlier, the UK Agriculture and Health ministers had assured the House of Commons that eating British beef did not involve any risk: Health Minister Stephen Dorrell stated that the risk of contracting Creutzfeldt-Jakob Disease by eating beef was "very low" and he himself would continue eating it. However, as this followed years of the British Government assuring its citizens that there was no connection whatsoever between 
eating beef and contracting brain disease, the ministers' declarations did little good.

The British ministers made their statement to preempt a news conference about to be held by a government commission set up to study the relation between mad cow disease and brain illnesses in humans. In this news conference new scientific evidence would be announced indicating that "bovine spongiform encephalopathy" - commonly known as mad cow disease - could be transmitted to human beings. The Commission stated that there was no evidence that this had indeed occurred, but the mere fact that it was possible was extremely worrying.

Beef sales plummeted throughout the European Union. In the UK, beef cattle sales fell by nearly $90 \%$ the week after the ban was declared. Two weeks later, beef prices had fallen by 20 to $50 \%$ throughout the countries of the European Union. Sales volumes had dropped even further, with consumption falling 50\% in Belgium, 30\% in France, 50\% in Portugal and $60 \%$ in Italy. In Germany, where there had long been concern among consumers about mad cow disease, beef sales ground to a virtual halt. European export markets also were threatened, with Ghana and Libya among others responding by banning all European beef, regardless of whether it was British or not.

\subsection{Background}

Bovine Spongiform Encephalopathy (BSE) belongs to a group of degenerative illnesses that attack animals' brains. The human equivalent is Creutzfeldt-Jakob Disease (CJD), an extremely rare disease, affecting on average one person in a million, particularly the elderly.

During the previous decade, 160,000 cases of BSE were detected in British cattle, many more than elsewhere in the world, the next country being Switzerland with 206 cases. In fact, just $0.3 \%$ of BSE cases have been in non-British cows. British cattle probably contracted the disease by eating fodder made from brain, spinal cord and other sheep derivatives (BSE hides in the central nervous system). Sheep typically suffer from "scrapie", a BSE-related disease that has killed sheep and goats for centuries. 
The first case of BSE occurred in England in 1986. In 1988, with Britain's fields full of mad cows, the government banned the use of fodder based on dead animals (goats and sheep as well as cattle). It also warned of the potential hazards involved in people eating these animals' viscera, at the same time as it went on insisting that there was no relation whatsoever between BSE and CJD.

However, the way the British Government adopted these measures was inept. Among the mistakes it made in its handling of the BSE epidemic at the end of the eighties, at least four are worth mentioning. First, it only paid half the market value for infected cattle, which probably led many farmers to rush infected cattle to the slaughterhouse, rather than sell them to the government.

A second error was the slow enforcement of measures designed to prevent cows belonging to herds affected by BSE outbreaks from reaching the food chain. The same was true of measures to avoid slaughterhouse contamination. The third mistake was to keep insisting for a long time that there was no risk at all. An extreme example was Agriculture Minister, John Gummer, who fed a hamburger to his four-year old daughter in front of the television cameras.

A fourth mistake made by the British Government was to allow British slaughterhouses during the eighties to eliminate carcasses at very low temperatures, often less than 100 degrees centigrade, whereby potential sources of infection were not completely destroyed. This, despite the fact that in the early eighties a British commission of experts had suggested raising temperatures. Other countries require much higher temperatures.

Possible explanations for the BSE epidemic in the UK, therefore include: (a) this is one of the few countries that simultaneously have a large number of cattle and sheep; (b) historically the UK has had more scrapie among its sheep than any other country; and (c) temperatures for rendering down cattle carcasses in the UK were considerably lower than in other countries during the eighties. 


\subsection{New Scientific Evidence}

The evidence that led British scientists to argue for a possible link between BSE and CJD was the appearance of a new variant of CJD in the UK. Robert Will, director of a panel studying Creutzfeldt-Jakob Disease at the University of Edinburgh, and a member of the government panel, identified "an unknown and consistent pattern" of the disease in ten victims with CJD-type symptoms. None of the victims seemed to suffer from the genetic deficiencies commonly associated with the illness. Even more worrying was the fact that their average age was 27 years; all were under 42. Until this group was identified, the average age of those sick with CJD was 63 . The kind of brain damage, initial symptoms and disease duration were all different from earlier cases.

This led scientists to conclude that, in the absence of a better explanation, these cases could be the result of contagion via infected beef. There was no proof that this had in fact occurred, and it was possible that the new form of the disease had been identified in the UK simply because British scientists were studying the disease much more assiduously than their peers elsewhere.

There was great uncertainty about how many British people could be incubating this new variant of CJD if the cattle population infected with BSE really was responsible. Even if cow to human contagion was difficult, millions of people could have been exposed to BSE-infected cows before 1988, the year in which the British Government introduced measures to eradicate contaminated cattle and banned the use of brains and spinal cords in products for human consumption. Even though the number of CJD cases was small, the disease's long incubation period - estimated at between five and ten years - made it difficult to predict what would happen. John Pattison, director of the government advisory committee, ventured the opinion that "it would indeed be a question of a large-scale epidemic."

Another scientist estimated that the number of British deaths from the disease in the future at "between 500 and 500,000 per year," a reflection of scientists' almost total ignorance on the issue. 


\subsection{John Major vs. the European Union}

The real problem facing the British Government was in weighing the costs of alternative measures against their potential benefits, faced with a situation characterized by great uncertainty that was hard to quantify.

A basic solution required answers to two key questions. Firstly, how many people were infected by the human version of BSE during the eighties, before the British took measures to prevent suspicious material from entering the food chain? Secondly, is there any risk in eating beef today?

As for the first question, the British Government said virtually nothing during the initial months following the ban, but then there was little it could say to calm people's fears.

As to whether the authorities took sufficient measures to ensure people were sufficiently protected from then on, the biggest risks were posed by non-compliance with the rules adopted at the end of the eighties, and the possibility of infected animals without visible symptoms reaching slaughterhouses. The solution to the first problem was to improve enforcement, but the only way to prevent the second problem would be to slaughter the entire beef cattle population, since certainly there were cows carrying the disease in a state of incubation. Nonetheless, it was clear that the number of individuals incubating CJD from these causes was a tiny fraction of those who were infected before 1988.

The British Government's initial strategy to convince the European Union to lift the embargo was to deny that there was a problem. There was talk of a hysterical reaction on the part of their European partners and a plot to strike a blow against the efficient English beef export industry. This strategy, if it can be called such, produced few results. The British Government's frustration became clear nearly a month after the embargo was declared, when British Prime Minister John Major referred to the European ministers as "a bloody bunch of shits." 14

¿From the outset, the European Union made it clear it would share the cost of any solution to the mad cows crisis. There was a precedent for this when, during an outbreak 
of swine fever in Germany, the EU agreed to bear $70 \%$ of the cost. Although the UK initially sought compensation of $80 \%$ of the cost of any animal culled (somewhat ironic given that in the German case, the British Government thought that $70 \%$ of the costs had been excessive), it quickly agreed to a split whereby Britain paid $30 \%$ and the EU the remaining $70 \%$.

Agreement on actions to achieve the lifting of the ban was considerably more difficult than sharing the costs of such measures. On April 16th, British Agriculture Minister, Douglas Hogg, announced a package of minimal measures. Cows over 30 months old would be kept out of the food chain after being slaughtered, and measures from the eighties were to be more firmly enforced. This policy was designed more at the behest of meat producers than consumers. Producers went on selling beef from BSE-infected herds and the UK's proposed measures did little to satisfy their European partners.

Eventually the British Government began to consider taking reprisals. This idea split Prime Minister Major's party between the pro- and anti-Europeans ("Eurosceptics"), because of the effects such a policy would have on relations between the UK and the rest of the EU. In the end, the idea of taking retaliatory actions bordering on the illegal against the EU prevailed among the British Government. On May 22nd, the British embassy in the EU announced it would start to block Community activities in meetings of the permanent representatives who briefed the EU's Council of Ministers. In practice, this meant blocking all decisions requiring unanimous approval.

A terse announcement from London stated that "the Prime Minister hopes that there will be an agreement at the Florence summit for a partial lifting of the ban on beef products and a definitive timetable for lifting the general embargo. In the meantime, the UK's capacity to cooperate in European Union matters is impaired."

Declarations in response to the British policy of non-cooperation suggested that a solution would be negotiated before the EU summit in Florence on June 20th and 21st. If the impasse remained unresolved, the European partners would begin to "retaliate against the British," announced Jacques Santer, European Commission President. 
On Monday June 3rd, six of the 15 EU member states meeting in Luxembourg opposed lifting the ban on exports of gelatin, tallow and semen from British cattle. Germany, Austria, Portugal, Holland, Belgium and Luxembourg all opposed relaxing the embargo, thereby preventing the qualified majority needed for approval of this type of decision. The European Commission now had only a fortnight to adopt a decision that would satisfy the British. In the meantime, EU members' exasperation with the UK became clear: on June 9th Jacques Santer told the British newspaper The Observer that "the EU is reaching a moment of truth. We are reaching the limit of our tolerance."

By mid-June, signs of compromise began to emerge. The UK presented a new plan for lifting the export ban and relaxing its veto on EU decisions. On June 18th, the Community executive approved a document prepared by European Agriculture Commissioner, Franz Fischler of Austria, establishing the conditions the UK must meet, in order to start relaxing the export ban. These included requiring the branding of all beef cattle herds and a ban on the use of cattle, sheep or goat offal in animal feed. It also required that all cows be incinerated on completing their productive life at 30 months of age and a selective cull of over 100,000 head of cattle.

The Commission declared that it did not accept the British demand to lift the embargo on its exports to third countries, saying that authorization of British beef exports to third countries could only be granted once the EU had lifted its own ban.

On June 19th, the European Commission finally approved the British plan to control mad cow disease. EU President, Jacques Santer, declared himself satisfied with the European Veterinary Committee's approval of Britain's proposed sanitary measures, and the London plan received unanimous approval after twelve hours of debate. The motion immediately ended the embargo on exports of gelatin, tallow and semen from British cattle and included a gradual lifting of the embargo on the export of other derivatives as well as British beef itself.

Apart from incineration of several million head of cattle on completion of their active life, the plan included the culling of about 100 thousand animals born between 1989 and 
1990, still active in the reproductive cycle. It also involved an effective program of cattle identification, as well as controls to keep meal of animal origin out of beef cattle feed. At the same time, the UK ended its non-cooperation policy, whereby more than 90 issues being dealt with in the EU had been blocked.

\section{LESSONS AND A NEW DEFINITION OF PROTEC- TIONISM}

\subsection{Comparison of the Two Case Studies}

Following the declaration of the two embargoes discussed above, both Chile and the UK took immediate steps to eliminate risks to consumers. In both cases, these were situations of great uncertainty, difficult to quantify. Were there more contaminated grapes out there, and if so how many? How many British citizens were incubating CJD? Could beef currently being consumed by the British people be BSE-contaminated? Chile increased phytosanitary controls, whereas the UK tightened supervision of sanitary measures adopted at the end of the eighties.

What stands out when comparing the two case studies is the striking difference between Chile and the UK when it came time to negotiate. The relative weakness of Chile's bargaining position is evident: whereas the UK adopted an uncooperative attitude within the European Union, boycotting much of the Union's work for several weeks, it took the Chilean delegation three days after the FDA ban to be received by a high-level government authority in the US (Secretary of State, James Baker). Moreover, the US authorities have systematically refused to cooperate with requests from the Chilean judicial system, and the Chilean Government has met with little success in pressing its legal claims against the US Government, which successfully appealed on the grounds of "jurisdictional immunity" and then refused to invoke the 1914 Bryan-Suárez Mujica Treaty to resolve the dispute.

The European Union's offer to pay for $70 \%$ of a selective cattle cull contrasts with 
the fact that, today, over a decade later, Chile has still received no compensation from the US. Furthermore, one year after the grape crisis, when evidence pointing to at least some degree of negligence on the part of the FDA became public, the US Senate rejected legislation that would have established equal conditions for the inspection of Chilean fruit, and approved an extension of the marketing orders required for kiwis, plums, nectarines and apples imported into the United States.

\subsection{Commissioner Young's Decision}

It has been widely argued in Chile that the FDA's measure was disproportionate, and that in more serious cases it had not adopted such draconian steps. To quote the report of the Chilean Chamber of Deputies, this was a "hasty and exaggerated measure" which caused serious economic damage. "From all of this one can conclude, with considerable certainty, that there was manifest bad faith on the part of the US authorities in facing up to the situation" (p. 24 of the report).

I argue below that Commissioner Young's behavior might have been justified given the conditions he faced. In doing so, I put myself in the commissioner's shoes, with the information available to him on March 13th 1989 when the poisoned grapes were discovered. I assume that Young did not participate in any plot directed against Chile and reflect on what his decision-making process might have been.

A first possibility is that he conducted a cost-benefit analysis. What were the costs

of ordering an embargo and what were the benefits? Benefits included the possibility of saving the lives of US citizens. The probability of a child dying from eating fruit injected with cyanide was small, but certainly not zero; if two grapes were found to be contaminated and there had been telephone threats in Santiago, he could not rule out the possibility of more poisoned grapes headed for the tables of US consumers. As well, eating the poisoned fruit could damage health, without necessarily killing someone.

What were the costs of an embargo? US consumers would have to assume the costs of not being able to consume Chilean fruit for a given period, and having to pay a higher price 
for fruit imported from elsewhere, or else having to replace fresh for other produce (e.g. canned fruit). There was also the second area of costs arising from the ban: the enormous losses to Chilean producers. ¿From Commissioner Young's point of view, however, this cost was practically irrelevant, for his mission was to protect the health of US citizens and did not encompass the measures' impact on foreign producers. The ban also imposed costs on US firms (e.g. distributors of Chilean fruit), but these costs were minor compared with those faced by Chilean producers. This kind of analysis leads us to conclude that the ban was warranted on cost-benefit grounds alone, with no plot or conspiracy theory necessary to justify it.

A second analytical process open to Commissioner Young would also have led to a ban. This one is based on his opting for the measure posing the least risk to his position. If we assume that the Commissioner's goal in deciding whether or not to impose the embargo was to avoid putting his job on the line, how would he have acted? This analysis requires comparing costs associated with different options if these proved mistaken. The first option, for example, would be to avoid a ban and then face the consequences of consumers getting poisoned. Public outrage would have been huge; public opinion would have concluded that Commissioner Young, knowing of the possible existence of poisoned fruit, had nonetheless learned nothing from the recent PanAm disaster. He would probably have lost his job.

A second misjudgment would involve declaring the embargo, without sufficient justification. In this case, the big losers would be Chilean producers, who posed no threat to the FDA director's position. Insofar as the available evidence admitted "reasonable doubt" about the safety of Chilean fruit, the most advisable course of action was to impose the ban.

It is worth contrasting the incentives faced by Commissioner Young with those facing European Union Commissioner Fischler when he called for the ban on British beef exports. Fischler did not work for any government in particular but was an official of the European Commission, for which reason he had to put Community interests above those of individual 
member countries. It was therefore not surprising that well before agreeing on the measures that the UK should apply so the EU would approve the gradual lifting of the ban, the countries had agreed on how to share the costs of these measures. The EU also had a precedent set by a similar situation in which the EU had paid $70 \%$ of the costs; it was therefore natural to apply similar criteria in this case.

It is true that the mad cow case generated considerable tension between John Major's Government and the EU regarding the measures to be taken, with Major embarking on a course of obstructionist actions bordering on the illegal. However, Major's behavior seems to have been driven primarily by political considerations within his party, rather than being a reaction to exaggerated demands from Britain's trading partners.

The main difference between the situations faced by the two commissioners was that Young had almost no incentive to consider the impact of the ban on the exporting country, while Fischler did.

\subsection{The Measures Taken and Protectionism}

Were the measures adopted by the US against Chilean fruit, or by the EU against British beef protectionist? This section offers answers to these questions, and in doing so offers a new definition of what constitutes a protectionist measure.

There is no agreement on the best definition of a "protectionist measure" or, in particular, a non-tariff barrier to trade. The most general definition is credited to Walter (1972) (quoted by Chambers and Pick [1994]), who defines it as any measure that distorts the volume of trade, the composition of the basket of goods traded between countries, or the direction in which goods are traded. Using this definition, both the embargo imposed by the FDA and that applied by the EU were protectionist measures. However, this definition is clearly too general, since any measure legitimately seeking to protect consumer health by banning imports of a risky product would thus be protectionist.

A second definition is provided by Baldwin (1970), also quoted by Chambers and Pick (1994). Baldwin focuses on a measure's effect on a country's real income and defines 
a non-tariff trade barrier as any measure (public or private) other than a tariff "which leads to internationally traded goods or services being reallocated in such a way that global potential real income is reduced." Under this definition, it seems natural to venture the opinion that the FDA ban constituted a protectionist measure, at least given the information available ex-post (there were no more poisoned grapes). In the case of the ban on British beef the situation is less obvious. Once the new evidence of a possible link between BSE and CJD became known, would global real income have been reduced to a lesser extent without the embargo?

The third definition comes from Hillman (1991) (again quoted by Chambers and Pick [1994]), who defines a non-tariff barrier as "any decision or government practice, apart from the imposition of a tariff, which directly impedes the entry of imports into a country and/or discriminates against imports, i.e. a measure that is not applied equally to domestic producers or distributors."

The first half of the Hillman definition is similar to Walter's, for which reason we only consider the second half. Using this definition, neither embargo would constitute a protectionist measure, given that it can be argued that both commissioners had information justifying the ban in question, so the measure was not discriminatory. To prove otherwise, one would have to show evidence of similar situations involving US agricultural products, or those from European Union countries, where an embargo was not imposed. And even if such situations were found, there would always be differences between those cases and the ban in question, making it difficult to develop arguments along these lines.

Subsection 4.2 encourages us to seek a new definition of "protectionist measure," one in which a measure becomes "protectionist" when it differs (markedly) from the measures that would have been taken, if the welfare of all countries affected by the measure had been considered. ${ }^{15}$ That is to say, a government measure is protectionist when, allowing for transfers between countries, there exists a Pareto superior alternative. For example, and working in partial equilibrium, a minimum quality standard is protectionist when it differs from the standard that maximizes the sum of producer and consumer surpluses 
both in the country setting the standard and in the country exporting the targeted good.

Using the above definition, the ban on British meat could not be classified as a protectionist measure. From the outset, the European Union knew that it would assume a significant part of the cost of any measures, so there were incentives to impose a ban only if this would increase aggregate welfare in the EU. Moreover, the case study of Section 3 provides no evidence that the EU failed to act with the welfare of the Union in mind.

The status of the ban on Chilean fruit is far from clear. Under this definition, we need to know what Commissioner Young would have decided if he'd had some incentive to internalize the effects of a possible ban on the Chilean economy. There's no clearcut answer to this question, but it is likely that he would have chosen to seek more information - e.g. by calling a meeting of scientists to assess the potential health risk of the contaminated grapes - before declaring an embargo. If this is true, then the ban on Chilean fruit would qualify as a protectionist measure.

\section{CONCLUSION}

Among the new faces of protectionism are the trade measures that governments take, supposedly to protect the health of their citizens, without considering the disastrous effects these may have on the welfare of their trading partners. The US ban on Chilean fruit imports, discussed at length in Section 2, is an example of this type. The degree of integration within the European Union provided a solution to this new form of protectionism among its member countries, as the case study of Section 3 illustrates. The EU's decisions in the case of the mad cows did take into account the welfare of the affected exporting country (the UK). ${ }^{16}$

The two case studies considered in this paper motivated the new definition of protectionism discussed in Section 4, whereby one country's action (affecting other countries) may be considered protectionist when it differs from other possible measures that would maximize the collective welfare of all countries involved. This definition can be extend- 
ed in many directions. For example, Fischer and Serra (1997) applied it to the case or minimum quality standards, proposing that when standards are imposed on goods with externalities in consumption, the welfare of foreign consumers should not be considered when deciding whether a measure is protectionist.

The analysis of the previous sections also brings out the importance of creating mechanisms that provide officials with the incentives to internalize the cost of protectionist measures they might impose on exporting countries. Ideally, if countries were required to bear the costs of the measures they impose, the resulting policies should improve the aggregate welfare of all countries involved. Using the definition of protectionism proposed above, the result would be that with appropriate incentives, measures adopted would never be protectionist. 


\section{NOTES}

* University of Chile and NBER. This paper was partly written while the author visited the Center for Research on Economic Development and Policy Reform at Stanford University; the Center's hospitality is gratefully acknowledged. The author thanks Claudio Rammsy for outstanding research assistance, and Alexander Galetovic, James Hines, Anne Krueger, Pablo Serra and a referee for helpful comments and suggestions. Financial support from institutional grants to CEA from the Mellon and Hewlett Foundations is gratefully acknowledged. Address correspondence to: Center for Applied Economics (CEA), Dep. of Industrial Engineering (DII), University of Chile, Av. República 701, Santiago, Chile. E-mail: eengel@dii.uchile.cl.

1 This section is based on media reports. The main sources are cited in the notes.

2 Representative of the State of Pennsylvania, where the port of Philadelphia is located.

3 Report of the Investigating Committee, Chilean Chamber of Deputies, pp. 56-63.

4 See Basch and Engel (1993) for a description of the Copper Stabilization Fund. Although the report is not explicit about the destination of these sums, most likely it helped finance the purchase of external debt promissory notes by the Central Bank.

5 Darby and Karni (1973) make a similar point in the context of corporate fraud.

6 For example, the volume of exports to the US grew by $0.5 \%$ between 1985 and 1986 .

7 A similar conclusion is obtained if grape export revenues are considered instead of volumes.

$8 \quad$ El Mercurio, March 26, 1989.

$9 \quad$ The Wall Street Journal, November 16th, 1989. 
10 This treaty provides a mechanism for resolving disputes between both countries. It can be applied only when both countries agree to invoke it.

11 La Segunda, July 16th, 1989.

12 "Alar" is a chemical product harmful to health.

13 Sources for this section are contemporary press agency dispatches and articles from The Economist.

14 The Economist, April 27, 1996.

15 Of course, there is the implicit assumption that the measure makes foreign countries worse off than they would be under the "world welfare maximizing" alternative.

16 Integration will be of less help in cases where differences in safety standards across countries are relevant. For more on the relation between harmonization and welfare see the collection of essays in Bhagwati and Hudec (1996). 


\section{References}

[1] Baldwin, R.E., (1970): Nontariff Distortions of International Trade. Washington, D.C.: The Brookings Institution.

[2] Basch, M., and E. Engel, (1993): "Temporary Shocks and Stabilization Mechanisms: The Chilean Case." Chapter 2 in Engel, E. and P. Meller (eds.), External Shocks and Stabilization Mechanisms, Washington, D.C.: Johns Hopkins.

[3] Bhagwati, J.N., and R.E. Hudec, (1996): Fair Trade and Harmonization: Prerequisites for Free Trade?, Cambridge, Mass.: MIT Press.

[4] Chambers, R.G., and D.H. Pick, (1994): "Marketing Orders as Nontariff Trade Barriers". American Journal of Agricultural Economics, 76, 47-54.

[5] Darby, M.R., and E. Karni, (1973): "Free Competition and the Optimal Amount of Fraud," Journal of Law and Economics, 16, 67-88.

[6] Fischer, R., and P. Serra, (1997): "Protection and Standards" (in Spanish). Chapter 3 in R. Fischer (ed.), The New Faces of Protectionism, Santiago: Dolmen.

[7] Hillman, J.S., (1991): Techincal Barriers in Agricultural Trade. Westview.

[8] Walter, I., (1972): "Nontariff Protection Among Industrial countries: some Preliminary Empircal Evidence," Economia Internazionale, 25, 335-54. 
Table 1: GROWTH RATES OF CHILEAN GRAPE EXPORTS (QUANTUM IN \%)

\begin{tabular}{lccccccccc}
\hline \hline & 1986 & 1987 & 1988 & 1989 & 1990 & 1991 & 1992 & 1993 & 1994 \\
\hline To the US: & 0.5 & 15.7 & 24.9 & -2.5 & 36.9 & -18.2 & -3.0 & 1.1 & -1.9 \\
To the rest of the world: & -2.2 & 23.6 & 42.9 & 11.8 & 22.9 & 10.8 & 13.7 & 5.8 & 14.9 \\
\hline
\end{tabular}

Source: Central Bank of Chile. 